\title{
Development of excitatory backward associations during the establishment of forward associations in a delayed conditional discrimination by pigeons
}

\author{
THOMAS R. ZENTALL, LOU M. SHERBURNE, and JANICE N. STEIRN \\ University of Kentucky, Lexington, Kentucky
}

\begin{abstract}
The development of excitatory backward associations in pigeons was demonstrated in three experiments involving conditional discriminations with differential outcomes. In Phase 1 of all three experiments, correct comparison choices following one sample were followed by food, whereas correct comparison choices following the other sample were followed by presentation of an empty feeder. In Phase 2, the food and no-food events that served as outcomes in Phase 1 replaced the samples. When the associations tested in Phase 2 were consistent with the comparison-outcome associations developed in Phase 1, transfer performance was significantly better than when the Phase 2 associations were inconsistent with the Phase 1 associations. In Experiment 1, an identity matching-to-sample task was used with red and green samples and red and green comparisons. In Experiment 2, a symbolic matching task was used with shape samples and hue comparisons, and it was shown that the backward associations formed were between the trial outcome (food or no food) and the correct comparison. In Experiment 3, it was determined that the transfer effects observed in these experiments did not depend on either the similarity of behavior directed toward the samples in the training and test phases, or the similarity of food and no-food expectancies generated by the samples in Phase 1 to food and no-food events presented as samples in Phase 2.
\end{abstract}

In a backward conditioning procedure, presentation of an unconditioned stimulus (US) is followed by the presentation of a presumably neutral stimulus (CS). Backward conditioning is said to have developed when, relative to the appropriate control conditions, the CS evokes a change in behavior (i.e., a conditioned response, CR).

Until relatively recently, the ability to demonstrate backward conditioning has been questioned (see, e.g., Mackintosh, 1974) in spite of some evidence for it (e.g., Razran, 1956). Spetch, Wilkie, and Pinel (1981) have suggested that the failure to acknowledge the effectiveness of backward conditioning may result not only from the inconsistency with which the phenomenon has been reported, but also from the fact that the existence of backward conditioning is incompatible both with several traditional views of classical conditioning (e.g., Hull, 1943), and with contemporary views of classical conditioning that stress the predictive relation between the CS and US (e.g., Rescorla \& Wagner, 1972).

This research was supported by National Science Foundation Grants BNS-8418275 and BNS-9019080 to T. R. Zentall and P. J. Urcuioli, by National Science Foundation Grant RII-8902792 to J. N. Steim, and by a grant from the University of Kentucky Research Foundation to T. R. Zentall. We thank P. J. Urcuioli for a suggestion that led to the design of Experiment 1. We thank Karen Roper, Christopher Randall, and Zhongbiao Zhang for their help in running pigeons. Requests for reprints should be sent to Thomas R. Zentall, Department of Psychology, University of Kentucky, Lexington, KY 40506.
Recently, Hearst (1989) exposed pigeons to a backward conditioning procedure in which a red keylight followed food presentation and nothing followed no food (hopper light), or the reverse (i.e., red keylight followed no food). Although there was little pecking to the red keylight as a result of this treatment, when the pigeons were then presented with forward pairings of red keylight followed by food, the birds that had experienced the backward conditioning procedure began pecking the red keylight faster than the group that had not experienced food-red-keylight pairings.

One problem with training that involves such Pavlovian pairing of stimuli (US-CS) is that when one tests with the CS alone, it is not clear what the nature of the CR should be. When pairing occurs in the forward direction, the CR is often closely related to the UR. However, as noted by Matzel, Held, and Miller (1988), the problem with demonstrating the development of backward associations with the Pavlovian procedure "is that the response elicited by a CS is not necessarily indicative of the underlying associative strength of that stimulus, but may also depend on the appropriateness of the response given the temporal relationship of the CS and US" (p. 338). In other words, it may be difficult to specify what response would indicate the establishment of a US-CS association. Evidence for the establishment of a US-CS association may have to be observed in facilitated acquisition (in Phase 2, relative to controls) of a CS-US association (see, e.g., Hearst, 1989). 
One way to avoid this problem is to examine the development of relations between arbitrary (i.e., nonhedonic) stimuli in a conditional discrimination. This approach to the problem of directionality of relations between stimuli has a long history in human verbal learning (see, e.g., Asch \& Ebenholtz, 1962). If humans learn a list of paired associates (i.e., a correct response to the presentation of Stimulus 1, S1, is Response 1, R1, etc., where $\mathbf{S}$ is a visually presented verbal item, such as a printed word, and $R$ is a spoken response), they are apparently also able to give the spoken response S1 when they are presented with the visual stimulus R1.

This paired associate procedure differs in a number of important ways from studies of backward associations done with a Paviovian conditioning procedure. First, the task used with humans is clearly instrumental. Second, the task actually involves a conditional rather than a simple discrimination, because the nature of the response depends on which of a number of stimuli has been presented. Finally, in the human learning task, the stimulus and response items are, at least in principle, interchangeable (i.e., response items in training could just as easily have been stimulus items), whereas the order of CS-US presentation is not arbitrary, because of the inherent difference in hedonic value that typically exists between the CS (e.g., light or tone) and the US (e.g., shock or food).

In spite of these procedural differences, the underlying question being asked in both lines of research is the same. Given training involving two stimuli that have been presented in one temporal arrangement, is there any evidence that a learned relation between these two stimuli can be demonstrated when they are later presented in the reverse temporal order?

Backward associations have also been examined in pigeons following the acquisition of conditional discriminations (Hogan \& Zentall, 1977; Richards, 1988). Hogan and Zentall trained pigeons on a conditional discrimination involving red and green conditional stimuli (samples) presented on a center response key and blue and yellow test stimuli (comparisons) presented on left and right response keys. Whether responses to blue or yellow were correct was contingent on whether the sample on that trial was red or green. Once the task had been learned, the blue and yellow stimuli were presented on the center key and the red and green stimuli were presented on the side keys.

Little evidence of backward associations was found by Hogan and Zentall (1977) in two of their three experiments, and the transfer effects reported in the third experiment disappeared after the first $\mathbf{1 6}$ transfer trials. In general, the pigeons performed no better than chance. Furthermore, pigeons for which the purported backward associations were appropriate to the transfer task acquired that task no faster than did pigeons for which those associations were inappropriate to the transfer task (see Richards, 1988, for similar minimal evidence for the development of backward associations).

One problem in interpreting the results of these experiments is that evidence for the development of backward associations was assessed without allowing animals experience with the test stimuli in locations (or under conditions) similar to those to be experienced during test. For example, Hogan and Zentall (1977) tested pigeons with samples appearing for the first time on the side keys and comparisons appearing for the first time on the center key (see also D'Amato, Salmon, Loukas, \& Tomie, 1985, for a similar problem in testing for evidence for the development of backward associations in monkeys). On the other hand, even when pigeons have experienced individually presented stimuli in the locations appropriate to the transfer test, evidence for the development of backward associations has not been found (Lipkens, Kop, \& Matthijs, 1988). But as these authors note, presenting the stimuli individually may be quite different from presenting them in the context of a conditional discrimination task. However, even when animals have been preexposed to the transfer stimuli in their appropriate locations and in the context of conditional discriminations (the animals received additional training with identity matching involving all of the stimuli), evidence for the development of backward associations was not found (Sidman et al., 1982).

It may be that the bidirectional associations that develop between arbitrary stimuli in the delayed matching-tosample (DMTS) task are not sufficiently strong to be demonstrated in a transfer task. It is possible that the development of strong backward associations in pigeons, unlike in humans, depends on the presence of a hedonic stimulus as one of the two associated events. As mentioned earlier, however, the behavioral change indicative of the formation of a bidirectional association may be difficult to specify. A solution to this problem is to use hedonic stimuli in the context of an instrumental task (e.g., DMTS) in which a specifiable response is trained. For example, if in training, correct responses to one comparison are followed by food, whereas correct responses to the alternate comparison are followed by no food (a differential outcomes procedure; see Trapold, 1970), evidence for the development of a bidirectional association would consist of choice of the first comparison when food is presented as the sample and choice of the alternate comparison when no food is presented as the sample.

The purpose of the present experiments was to determine whether one can demonstrate the presence of bidirectional associations acquired during the training of a conditional discrimination involving differential outcomes associated with the two sample/correct-comparison responses. The assumption was that if bidirectional associations developed between the differential outcomes and their associated correct comparisons, then substitution of those outcome events for the samples used in training should result in transfer effects that would demonstrate the presence of the backward associations.

It is also possible that in the earlier research involving arbitrary stimuli, the exchange of sample stimuli originally presented on the center key with comparison stimuli originally presented on the side keys (e.g., Hogan \& Zentall, 1977) resulted in sufficient generalization dec- 
rement to obscure the demonstration of backward associations during test. By maintaining the location of the comparison stimuli on the side keys in both training and test and the food (and no food) events (outcomes during training and samples during test) at the grain hopper, one should avoid the generalization decrement due to changes in stimulus location between training and test.

\section{EXPERIMENT 1}

In Experiment 1, Phase 1 training involved an identity DMTS task with differential outcomes in which red samples indicated that a response to the red comparison would be followed by food and green samples indicated that a response to the green comparison would be followed by no food (i.e., an empty feeder), or vice versa (i.e., a correct response to green was followed by food; a correct response to red was followed by no food). In Phase 2, for the positive group (Group P), if correct comparison responses to red had been followed by food in training, then a response to the red comparison following a food sample was rewarded and a response to the green comparison following a no-food sample was also rewarded, whereas for the negative group (Group $N$ ), the opposite pairings were reinforced. If the establishment of red-food and green-no-food associations should result in the development of food-red and no-food-green associations, it was expected that Group P would show initial performance that was significantly better than that of Group $\mathrm{N}$.

\section{Method}

\section{Subjects}

Twelve experimentally naive White Carneaux pigeons obtained from the Palmetto Pigeon Plant (Sumter, SC) served as subjects. All were retired breeders (5-8 years old) of undetermined sex. The pigeons were housed individually in a colony room with a 12:12-h light:dark cycle, and they were maintained at $75 \%-80 \%$ of their free-feeding weights throughout the experiment. Water and grit were freely available to the pigeons in the home cages.

\section{Apparatus}

The experiment was conducted in a standard pigeon test chamber that measured $37 \mathrm{~cm}$ (high) $\times 34 \mathrm{~cm}$ (across the intelligence panel) $\times 30 \mathrm{~cm}$ (wide). Three response keys $(2.5 \mathrm{~cm}$ in diameter) were mounted in a horizontal row $10 \mathrm{~cm}$ from the top of the panel and were spaced $8.3 \mathrm{~cm}$ apart (center to center). Behind each response key was a 12-stimulus in-line projector (Industrial Electronic Engineering Model 10 with General Electric No. 1820 lamps) that projected white (W, no filter), red (R), and green (G) hues (Kodak Wratten filters Nos. 26 and 60, respectively). Three grain feeders, one containing split peas, one containing mixed grain, and the third empty but weighted, were mounted behind the intelligence panel in such a way that if any one of them was raised, it was accessible to the pigeon through a $5.1 \times 5.7 \mathrm{~cm}$ aperture horizontally centered on the panel. The bottom edge of the aperture was $7 \mathrm{~cm}$ above the wire mesh floor and was illuminated whenever any of the feeders was raised. A shielded houselight, mounted $4 \mathrm{~cm}$ above the response keys, provided general chamber illumination. Extraneous sounds were masked by white noise at $72 \mathrm{~dB}$ presented through a speaker mounted on the left side of the intelligence panel, and by the sound of an exhaust fan mounted on the exterior of the chamber. The experiment was controlled by a microcomputer located in an adjoining room.

\section{Procedure}

Pretraining. All pigeons were adapted to the operant chamber and were then trained to eat from the mixed-grain feeder whenever it was raised. They were then shaped by the method of successive approximation to peck $W$ on the center key. Once keypecking was well established, the stimulus on the center key was changed ( $R$ or $\mathrm{G})$ randomly following each reinforcement (12 presentations of each stimulus). Stimulus presentations were separated by a $10-\mathrm{sec}$ intertrial interval (ITI), with reinforcement presented during the first $2 \mathrm{sec}$ of the ITI. On the next day, on each of 24 presentations, the left or right key was lit with either $R$ or $G$, and a single response resulted in reinforcement.

Phase 1 training. On the day following the end of pretraining, all birds began training on a 0 -sec-delay DMTS task involving $R$ and $G$ samples and $R$ and $G$ comparisons with differential outcomes.

Each trial began with the $\mathrm{W}$ center key. A single peck to $\mathrm{W}$ caused the key to change to R or G for $6 \mathrm{sec}$. At the end of $6 \mathrm{sec}$, independently of the bird's behavior, the center key was extinguished and the side keys were lit $\mathrm{R}$ and $\mathrm{G}$. For half of the birds $(n=6)$, pecks to the $\mathrm{R}$ comparison following an $\mathrm{R}$ sample were followed by 2 -sec access to split peas (food) and pecks to the $G$ comparison following a $\mathrm{G}$ sample were followed by a 2 -sec presentation of an empty feeder (no food). For the remaining birds $(n=6)$, pecks to the $R$ comparison following an $R$ sample were followed by no food, whereas pecks to the $G$ comparison following a $G$ sample were followed by food. For all birds, pecks to the $\mathrm{G}$ comparison following an $R$ sample and to an $R$ comparison following a $G$ sample were followed by the ITI alone. These responses were defined as incorrect and they resulted in the repeated presentation of that trial (correction procedure). For purposes of calculating performance, only the first presentation of each trial was counted.

Sessions ( 96 trials each, counterbalanced in blocks of 16) were conducted 6 days a week and were counterbalanced for sample hue and position of the correct comparison. Trials were presented randomly, with the constraint that no more than three consecutive trials involved the same sample hue or the same correct comparison location.

Each pigeon was trained on this task for a minimum of 8 days and to a criterion of two consecutive sessions at a performance level of $90 \%$ correct or better.

Phase 2 transfer. As the pigeons completed Phase 1, they were assigned to one of two groups in Phase 2 (Groups P and N). An attempt was made to assign the birds to groups on the basis of both their Phase 1 training experience (R-food vs. G-food) and the speed with which they acquired Phase 1 .

In Phase 2, the food and no-food outcome events from Phase 1 replaced the R and $G$ samples. For the birds in Group P, 2 sec of food (split peas) replaced the sample hue that was associated with the food outcome in Phase 1 (e.g., if in Phase 1, correct R matches were reinforced with food, then in Phase 2, following a food sample, responses to an $\mathrm{R}$ comparison were reinforced with mixed grain, whereas following a no-food sample, responses to a $\mathrm{G}$ comparison were reinforced with mixed grain). For the birds in Group $\mathbf{N}$, on the other hand, food replaced the sample hue that was associated with no food in Phase 1 (e.g., if in Phase 1, correct $R$ matches were reinforced with food, then in Phase 2, following a no-food sample, responses to an $\mathbf{R}$ comparison were reinforced, whereas following a food sample, responses to a $\mathrm{G}$ comparison were reinforced).

Thus, if the comparison-outcome associations acquired in Phase 1 give rise to backward associations (i.e., outcome-comparison associations), they should result in better Phase 2 transfer performance for Group P than for Group N. In Phase 2, the outcome following a correct response was always mixed grain, and a noncorrection procedure was used. In all other respects, trials in Phase 2 were the same as those in Phase 1.

Because food was presented as a sample on half of the trials in Phase 2 and mixed grain could be obtained following each correct response, the total trials per session was reduced to 64 in Phase 2. 
All pigeons were trained to a criterion of $90 \%$ correct or better on a single session.

\section{Results}

The pigeons acquired the Phase 1 identity-matching differential-outcome task to criterion in an average of 6.8 sessions. Whether $\mathbf{R}$ or $\mathbf{G}$ matches were followed by food did not affect the rate of acquisition $(F<1)$. Further, the two transfer groups did not acquire the Phase 1 task at significantly different rates $(F<1)$. The .05 level of significance was used in these and in all subsequent analyses.

In addition to analysis of choice performance, an analysis was performed on the number of pecks to each of the sample types (pooled over the last three sessions of Phase 1) for each bird, with sample (R vs. G) and outcome (food vs. no food) as factors. The analysis indicated that the pigeons pecked significantly more to the sample associated with food $(M=9.4$ pecks/trial) than to the sample associated with no food $(M=.7$ pecks/trial) $[F(1,10)=23.10]$; but there was no significant effect of sample $(F<1)$, and there was no significant sample $X$ outcome interaction $(F<1)$.

In Phase 2, performance on the first block of 16 transfer trials of Session 1 was at a significantly higher level for birds in Group P ( $M=56.2 \%$ correct) than it was for birds in Group N $(M=33.3 \%$ correct $)[F(1,10)=$ 20.86]. This difference was also significant when the data were pooled over the first transfer session (96 trials) of Phase $2(M=60.5 \%$ and $42.5 \%$ correct for birds in Groups $\mathrm{P}$ and $\mathrm{N}$, respectively) $[F(1,10=9.37]$. The transfer results of Experiment 1 are presented in Figure 1.

The magnitude of the transfer effect may actually be greater than the difference in performance between Group P and Group N seems to suggest. Because one of the comparisons in Phase 1 was associated with a food outcome and the other with a no-food outcome, most of the

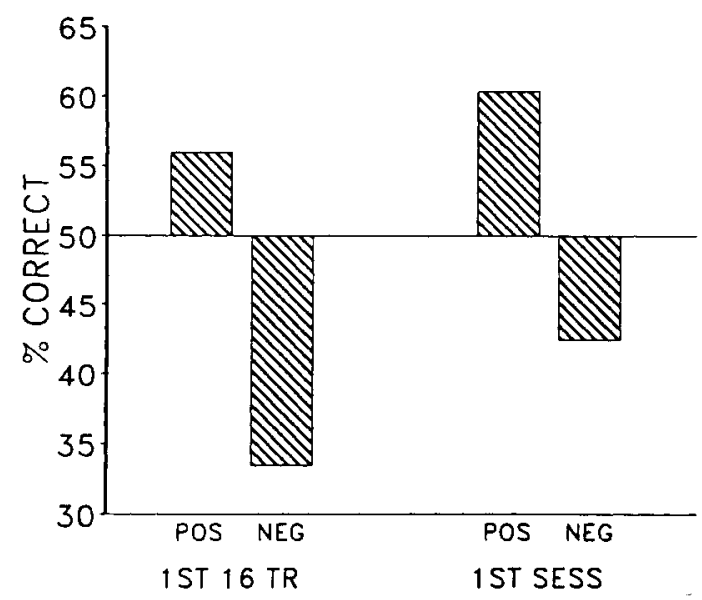

Figure 1. Experiment 1: Transfer performance by Groups $P$ and $N$ on the first 16 trials of Phase 2 (left) and on the first session of Phase 2 (right). birds in Phase 2 showed some bias to respond to the comparison associated with food (regardless of the sample).

An unbiased estimate of the transfer effect (i.e., one that corrects for the preference for the food-associated comparison) is the percentage correct responding given a response to the least preferred comparison. When this subset of the Session 1 transfer data was examined, the difference in performance between Group $\mathrm{P}(M=66.8 \%$ correct) and Group N ( $M=36.7 \%$ correct) was significant $[F(1,10)=11.83]$, and it was quite a bit larger (mean difference $=30.1 \%$ correct) than it was when all the data from Session 1 were considered (mean difference = $18.0 \%$ correct).

\section{Discussion}

The difference in transfer performance between Groups $P$ and $N$ (22.5\% correct over the first 16 trials, and $18.0 \%$ correct over the first transfer session) suggests that the forward pairing of a comparison stimulus and hedonic outcome can give rise to a backward association between the two that can be observed when the outcomes are substituted for the samples, and that the food/no-food samples thus serve to signal which comparison stimulus is correct. We propose that the forward pairings that are involved in the development of the backward associations occur between the correct comparison and the outcome that follows responses to it. However, given the identity relation between the samples and correct comparisons in Experiment 1, one could also argue that forward sampleoutcome pairings were responsible for (or played a critical role in) the development of the backward associations that were found.

\section{EXPERIMENT 2}

In Experiment 2, a conditional discrimination with differential outcomes was used to determine the role played by comparison-outcome associations in the development of backward associations. The shape samples (circle and dot) used in Experiment 2 were only symbolically related to the hue comparisons ( $R$ and $G$ ). If the backward associations found in Experiment 1 resulted from the forward pairing of comparisons with outcomes, one should see similar differences in transfer performance between positive and negative groups when pigeons are trained on a conditional discrimination involving a nonidentity relation between samples and comparisons.

\section{Method}

\section{Subjects}

The subjects were 12 experimentally naive White Carneaux pigeons similar to those used in Experiment 1. They were housed and maintained as were the birds in Experiment 1.

\footnotetext{
Apparatus

The apparatus was the same as that used in Experiment 1, with the exception that two stimuli, a circle and a dot, were added to the center projector. The circle $(C)$ was a white annulus with a 16-mm outside diameter and a 13-mm inside diameter. The dot (D) was a white disk with a $5-\mathrm{mm}$ diameter.
} 


\section{Procedure}

The procedures used in pretraining and in Phases 1 and 2 were the same as those used in Experiment 1, with the following exceptions. All pigeons were pretrained to peck the $C$ and $D$ stimuli on the center key. In Phase 1 training, D replaced the $R$ samples and $C$ replaced the $G$ samples used in Experiment 1. In Phase 2, food (split peas) and no food (empty feeder) replaced the $C$ and D samples, so that an equal number of birds from the two counterbalancing groups in Phase 1 (i.e., D-R-food, C-G-no-food and D-R-nofood, $\mathrm{C}-\mathrm{G}-$ food) were represented in each of the transfer groups in Phase 2 (i.e., Groups $\mathrm{P}$ and $\mathrm{N}$ ).

\section{Results}

The pigeons acquired the symbolic conditional discrimination to criterion in an average of 9.2 sessions. Again, neither the two counterbalancing groups nor the two transfer groups differed significantly in the rate at which they acquired the Phase 1 task (both $F \mathrm{~s}<1$ ).

Again, an analysis was performed on the number of pecks to each of the sample types pooled over the last three sessions of Phase 1, with sample (circle vs. dot) and outcome (food vs. no food) as factors. The analysis indicated that the pigeons again pecked significantly more to the sample associated with food $(M=12.1$ pecks/trial) than to the sample associated with no food $(M=1.1$ pecks/ trial) $[F(1,10)=23.86]$, but again there was no significant effect of sample $(F<1)$, and there was no significant sample $\times$ outcome interaction $(F<1)$.

Analysis of the Phase 2 transfer data indicated that Group P performed at a significantly higher lever on the first 16 trials of Phase $2(M=54.2 \%$ correct) than did Group N $(M=40.6 \%$ correct $)[F(1,10)=4.98]$. A similar analysis performed on the data pooled over the first transfer session indicated a significantly higher level of performance for Group P $(M=56.2 \%$ correct) than for Group $\mathrm{N}(M=44.8 \%$ correct $)[F(1,10)=6.81]$. The transfer results of Experiment 2 are presented in Figure 2.

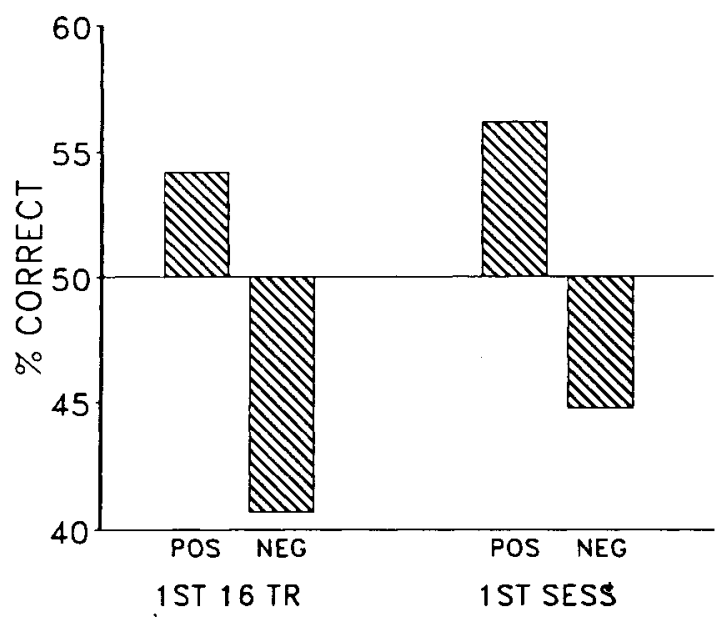

Figure 2. Experiment 2: Transfer performance by Groups $P$ and $N$ on the first 16 trials of Phase 2 (left) and on the first session of Phase 2 (right).
Again, when an unbiased estimate of performance transfer was examined (percentage correct responding given a response to the less preferred comparison), the difference in performance between Group $\mathrm{P}(M=62.2 \%$ correct) and Group $\mathrm{N}(M=40.5 \%$ correct) was significant $[F(1,10)=5.76]$, and it was larger (mean difference $=$ $21.7 \%$ correct) than when all the data from Session 1 were considered (mean difference $=11.4 \%$ correct) .

\section{Discussion}

The results of Experiment 2 confirm and extend the results of Experiment 1. Once again, evidence was found for the formation of backward associations following training in the forward direction. In addition, the results of Experiment 2 demonstrate that the basis of the backward associations was the forward pairing of the correct comparisons and the trial outcomes, rather than the forward pairing of samples and outcomes.

Although sample-outcome associations did not appear to be necessary to account for the backward associations demonstrated in Experiment 1, they clearly can play a role in the acquisition of conditional discriminations involving differential outcomes. There is good evidence, for example, that sample stimuli associated with similar outcome expectancies can be substituted for one another (Edwards, Jagielo, Zentall, \& Hogan, 1982; Peterson, 1984). Furthermore, the significant difference in pecking to samples associated with food versus no-food outcomes reported in both Experiments 1 and 2 suggests that the pigeons associate the samples with their respective outcomes and that the behavior they show toward the samples is directly indicative of the likelihood that they will be fed at the end of the trial. In the absence of a pecking requirement, these pigeons readily peck at samples that are associated with food outcomes and peck very little at samples that are associated with no-food outcomes. One can think of this phenomenon as an example of (delayed) autoshaping (Brown \& Jenkins, 1968).

In the backward association experiments presented here, is it possible that there is some topographical similarity between the response made to the sample associated with food (pecking the response key) and the response to food itself (eating; see, e.g., Jenkins \& Moore, 1973)? And similarly, is the response made to the no-food-associated sample similar to the response made to no food itself? If there is a similarity between the responses to the visual sample and its associated outcome, it is possible that the sample response could mediate the association between sample and correct comparison in Phase 1 of the present experiments. More importantly, to the degree that the food sample elicits a similar response, it could be that the differential transfer seen in Phase 2 of the present experiments is produced by response mediation rather than the presence of backward associations (Hogan, Pace, \& Zentall, 1983; Urcuioli \& Honig, 1980). In other words, if comparison choice in Phase 1 is influenced by the memory of having recently pecked (the sample) and in Phase 2 
the pigeon has a similar memory of having recently eaten (i.e., pecked the food), the similarity of these two events could be sufficient to account for the group differences found in Phase 2.

One further alternative to the backward association explanation for the present results needs to be addressed. It is possible that differential transfer effects found in Phase 2 of both Experiments 1 and 2 resulted from the similarity between expectations of food versus no food generated by the circle and dot samples in Phase 1 and the food versus no-food samples introduced during Phase 2. During acquisition of a conditional discrimination with differential outcomes, it has been suggested that with training, each sample comes to induce a central representation of the expected outcome on that trial (i.e., food or no food), and that the representation serves, in part, as the basis for comparison choice (Peterson, 1984; Trapold, 1970). Then, in transfer, the presentation of food and no-food samples also induces a central representation of food and no food, respectively. To the extent that the central representation of the expectation of food is similar to the central representation of food itself (and the same for representations of no-food expectancies and no food itself), one would expect the kind of transfer that was observed in Phase 2.

One could argue, of course, that pigeons should be able to discriminate quite readily between a stimulus that predicts that food will occur, and the actual occurrence of food. In other words, one would not expect a pigeon to be confused between the expectation of being fed and actually being fed. Evidence consistent with this hypothesis has been presented by Linwick, Overmier, Peterson, and Mertens (1988). Linwick et al. found that when pigeons were trained with food versus no-food samples and differential outcomes (of food and no food), delay performance did not depend on whether food samples were associated with food outcomes (and no-food samples with no-food outcomes) or food samples were associated with no-food outcomes (and no-food samples with food outcomes). On the other hand, it is still possible that events and their expectancies share a sufficient number of common features to result in the transfer effects observed.

One means of testing both this hypothesis and the notion that response mediation can account for the transfer data is to ask whether the relation between differential sample responding at the end of the training phase can (statistically) account for the magnitude of transfer effect found in Phase 2. An analysis of covariance (ANCOVA) was performed on the transfer data, with the average of the last three sessions of Phase 1 discrimination ratio (DR, i.e., number of pecks to the sample associated with a food outcome divided by the total number of sample pecks) as the covariate.

The ANCOVA performed on the Session 1 transfer data indicated that there was still a significant effect of transfer group $[F(1,9)=6.01]$. In fact, the correlation between DR in acquisition and transfer performance was actually quite low $(r=.03)$. Thus, it does not appear that either differential sample behavior or differential expectancies associated with the samples can account for the transfer effects.

One problem with this analysis is that the DRs for all birds were quite high (range $=.77$ to .97 ). When the range of the covariate is constrained, one is likely to underestimate the relation between the two variables. An alternative means of testing these hypotheses is to try to experimentally equate responding to the two Phase 1 samples.

\section{EXPERIMENT 3}

The purpose of Experiment 3 was to reduce differential responding between the two samples in Phase 1, and thereby to reduce the likelihood that both similarity of sample responding to outcome responding and similarity of outcome expectancy to the outcome itself could account for the differential transfer effects found in Phase 2 of Experiments 1 and 2.

The design of Experiment 3 was very similar to that of Experiment 2, with the exception that in each Phase 1 training session there were 24 additional trials in which the sample associated with no food (on conditional discrimination trials) was presented as a sample but was followed immediately by the presentation of peas and the ITI, rather than by the comparison stimuli (see Urcuioli \& Zentall, 1990, for a similar manipulation that was used to equate responding to samples). These additional trials were introduced to encourage the pigeons to associate both samples with food; thus, presumably, both food expectancies and pecking would be elicited in the presence of both samples.

\section{Method}

\section{Subjects}

Eight experimentally naive White Carneaux pigeons, similar to those used in Experiments 1 and 2, served as subjects. They were housed and maintained as in Experiments 1 and 2.

\section{Apparatus \\ The apparatus was the same as that used in Experiment 2.}

\section{Procedure}

The procedure used in Experiment 3 was the same as that used in Experiment 2 with the following exceptions. Each session during Phase 1 included, in addition to the 96 conditional discrimination trials with differential outcomes, 24 trials on which a single peck to the $W$ key produced the stimulus that served as the sample associated with the no-food outcome for that bird. Each of these 6-sec stimulus presentations was followed immediately by a $2-\mathrm{sec}$ presentation of peas and the ITI. In Phase 2, food and no-food samples replaced the circle and dot for Groups $\mathbf{P}$ and $\mathbf{N}$ as in Experiment 2 .

\section{Results and Discussion}

Pigeons acquired the Phase 1 conditional discrimination in an average of 12.4 sessions. As in Experiments 1 and 2, analysis of Phase 1 sessions-to-criterion data indicated that there was no significant effect of transfer group $(F<1)$. 


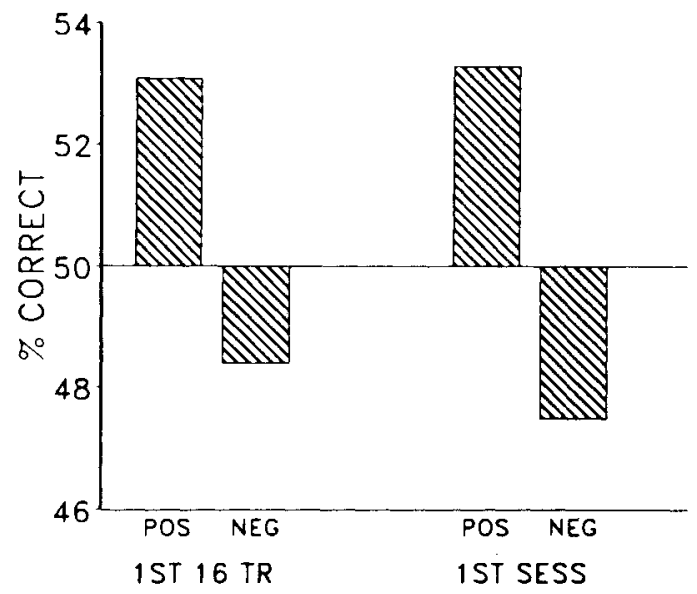

Figure 3. Experiment 3: Transfer performance by Groups $P$ and $N$ on the first 16 trials of Phase 2 (left) and on the first session of Phase 2 (right).

The additional pairings of food with the stimulus that served as the sample associated with no food appeared to produce the desired change in pecking to the two samples. The rate of pecking the food-associated sample $(M=$ $7.48 \mathrm{pecks} /$ trial) was not significantly different from the rate of pecking the no-food-associated sample $(M=6.63$ pecks/trial; $F<1$ ).

Transfer data indicated that Group $P$ performed at a higher level $(M=53.1 \%$ correct) than did Group N ( $M=48.4 \%$ correct) on the first 16 transfer trials, as well as over the first transfer session $(M=53.3 \%$ and $47.5 \%$ correct for Groups $\mathrm{P}$ and $\mathrm{N}$, respectively).

Once again, when an ANCOVA was performed on the data from both the first 16 trials and the first session of Phase 2, significantly higher levels of performance were found for Group P than for Group $\mathrm{N}$ with both measures $[F(1,6)=10.08$ and 11.86 , respectively $]$. Thus, the results of the present experiment indicate that one can find evidence of backward associations, even when comparable rates of sample responding have been produced in Phase 1 and any residual source of variance attributable to differential sample responding has been removed by means of an ANCOVA. The transfer results of Experiment 3 are presented in Figure 3.

Again when an unbiased estimate of performance transfer was examined with an ANCOVA, the difference in performance between Group P $(M=53.8 \%$ correct $)$ and Group N $(M=40.8 \%$ correct $)$ was significant $[F(1,5)$ $=8.10 \mathrm{~J}$, and the difference in performance was larger (mean difference $=13.0 \%$ correct) than when all the data from Session 1 were considered (mean difference $=$ $4.7 \%$ correct).

Although the results of Experiment 3 appear to rule out both response mediation and outcome expectancy explanations for the transfer effects observed, one could perhaps still argue that the outcome expectancies generated at the time of comparison choice have not been equalized. After all, on a no-food trial in original training, once the comparisons are presented, a no-food expectancy should be generated. Thus, it could be that food and no-food outcome expectancies generated by the presence of the comparison stimuli in Phase 1 are in some way similar to the memory for food and no-food samples at the time of comparison choice in Phase 2. But if this were the case, one would be claiming that at the time of the CS (i.e., comparison stimulus) presentation, a similarity exists between the expectancy of food (i.e., forward CS-US pairing) and the memory of food (i.e., backward US-CS pairing). In other words, one would be asserting that the comparison stimuli are each associated with two similar events-the expectancy of food (or of no-food) outcomes in the forward direction, and the memory of food (or of no-food) samples in the backward direction. If this hypothesis were correct, it would not provide an alternative account of the data, but rather, it would provide a mechanism by which backward associations develop.

\section{GENERAL DISCUSSION}

Evidence for the development of backward associations during training involving forward associations was found in three experiments. These experiments also provided evidence that backward associations can result from the forward pairing of correct comparisons and outcomes, and that they cannot be attributed (1) to sample-outcome associations (Experiment 2), (2) to the similarity between responses made to the visual samples in Phase 1 and responses made to the food and no-food samples in Phase 2 (Experiment 3), or (3) to the similarity of the expectation of food versus no food to the actual food versus nofood events (Experiment 3).

It has been demonstrated in previous research that the presentation of a US followed by a CS can result in the formation of a conditioned response to the presentation of the CS (e.g., Hearst, 1989; see also Spetch et al., 1981). Results from the present experiments demonstrate that forward stimulus pairings can result in the development of backward associations in a conditional instrumental discrimination.

The advantage that comes from using the conditional discrimination procedure with differential outcomes is that it may provide a better context for evaluating the establishment of backward associations than the traditional Pavlovian paradigm (i.e., US followed by CS). In the conditional discrimination procedure, original training involves learning to respond to both the foodassociated and the no-food-associated comparison stimuli. Thus, the mechanism for assessment of backward associations (i.e., the comparison choice response) is established in Phase 1, and one should be able to see immediate evidence for the presence of those associations when, in Phase 2, food and no-food events replace the samples from Phase 1.

The results of the present experiments add to the growing literature which indicates that trained associations between stimuli may be bidirectional in nature. Furthermore, they demonstrate that such associations can develop under conditions more varied than has previously been thought. 


\section{REFERENCES}

Asch, S., Ebenholtz, S. M. (1962). The principle of associative symmetry. Proceedings of the American Philosophical Society, 106, 135-163.

Brown, P. L., Jenkins, H. M. (1968). Auto-shaping the pigeon's key peck. Journal of the Experimental Analysis of Behavior, 11, 1-8.

D'Amato, M. R., Salmon, D. P., Loukas, E., \& Tomie, A. (1985). Symmetry and transitivity of conditional relations in monkeys ( $C e$ bus apella) and pigeons (Columba livia). Journal of the Experimental Analysis of Behavior, 44, 35-48.

Edwards, C. A., Jagielo, J. A., Zentall, T. R., \&ogan, D. E. (1982). Acquired equivalence and distinctiveness in matching to sample by pigeons: Mediation by reinforcer-specific expectancies. Journal of Experimental Psychology: Animal Behavior Processes, 8, 244-259.

HeArst, E. (1989). Backward associations: Differential learning about stimuli that follow the presence versus the absence of food in pigeons. Animal Learning \& Behavior, 17, 280-290.

Hogan, D. E., PaCe, G. M., \& Zentall, T. R. (1983). Control of pigeons' matching-to-sample performance by differential sample response requirements. American Journal of Psychology, 96, 37-49.

HogAN, D. E., \&ENTALl, T. R. (1977). Backward associations in the pigeon. American Journal of Psychology, 90, 3-15.

Hull, C. L. (1943). Principles of behavior. New York: AppletonCentury-Crofts.

JENkins, H. M., \& Moore, B. R. (1973). The form of the autoshaped response with food or water reinforcers. Journal of the Experimental Analysis of Behavior, 20, 435-441.

Linwick, D. J., Overmier, J. B., Peterson, G. B., \& Mertens, M. (1988). Interactions of memories and expectancies as mediators of choice behavior. American Journal of Psychology, 101, 313-334.

LiPKens, R., KoP, P. F., \& MATthius, W. (1988). A test of symmetry and transitivity in the conditional discrimination performance of pigeons. Journal of the Experimental Analysis of Behavior, 49, 395-410.

MACKINTOSH, N. J. (1974). The psychology of animal learning. New York: Academic Press.
Matzel, L. D., Held, F. P., \& Miller, R. R. (1988). Information and expression of simultaneous and backward associations: Implications for contiguity theory. Learning \& Motivation, 19, 317-344.

Peterson, G. B. (1984). How expectancies guide behavior. In H. L. Roitblat, T. G. Bever, \& H. S. Terrace (Eds.), Animal cognition (pp. 135-147). Hillsdale, NJ: Erlbaum.

Razran, G. (1956). Backward conditioning. Psychological Bulletin, 53, 55-69.

Rescorla, R. A., Wagner, A. R. (1972). A theory of Pavlovian conditioning: Variations in the effectiveness of reinforcement and nonreinforcment. In A. H. Black \& W. F. Prokasy (Eds.), Classical conditioning II: Current research and theory (pp. 64-99). New York: Appleton-Century-Crofts.

RICHARDS, R. W. (1988). The question of bidirectional associations in pigeons' learning of conditional discrimination tasks. Bulletin of the Psychonomic Society, 26, 577-579.

Sidman, M., Rauzin, R., Lazer, R., Cunningham, S., Tailby, W., \& CarRIGAN, P. (1982). A search for symmetry in the conditional discriminations of rhesus monkeys, baboons, and children. Journal of the Experimental Analysis of Behavior, 37, 23-44.

SPeTCH, M. L., WILkIE, D. M., \& PINel, J. P. J. (1981). Backward conditioning: A reevaluation of the empirical evidence. Psychological Bulletin, 89, 163-175.

TrapolD, M. A. (1970). Are expectancies based on different positive reinforcing events discriminably different? Learning \& Motivation, $1,129-140$.

URCuioli, P. J., \& HoniG, W. K. (1980). Control of choice in conditional discriminations by sample-specific behaviors. Joumal of Experimental Psychology: Animal Behavior Processes, 6, 251-277.

URCuioli, P. J., \& Zentall, T. R. (1990). On the role of trial outcomes in delayed discriminations. Animal Learning \& Behavior, 18, 141-150.

(Manuscript received October 9, 1991; revision accepted for publication February 5, 1992.) 